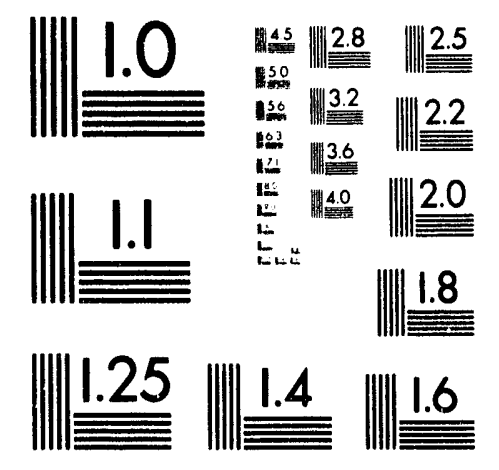



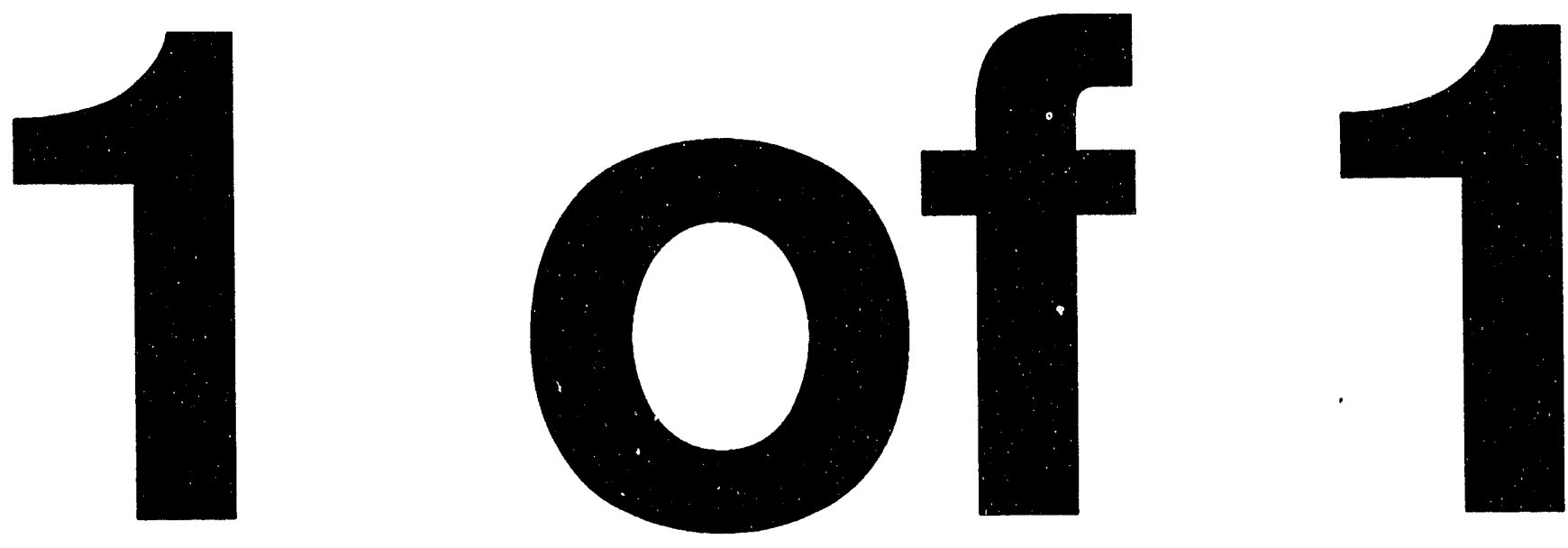


\title{
IMPACT STRENGTH AND INDENTATION HARDNESS OF HIGH-STRENGTH CERAMICS
}

\author{
D. E. Grady \\ Experimental Impact Physics Division 1433 \\ Sandia National Laboratories \\ Albuquerque, New Mexico, USA 87185
}

fugoniot elastic limit and indentation hardness data are provided for selected high-strength ceramics. The degree of correlation of the strength data by the two test methods is examined. The influence of leformation mechanism on the strength measurement, including rate sensitivity, size scale and confinng pressure, is discussed.

\section{INTRODUCTION}

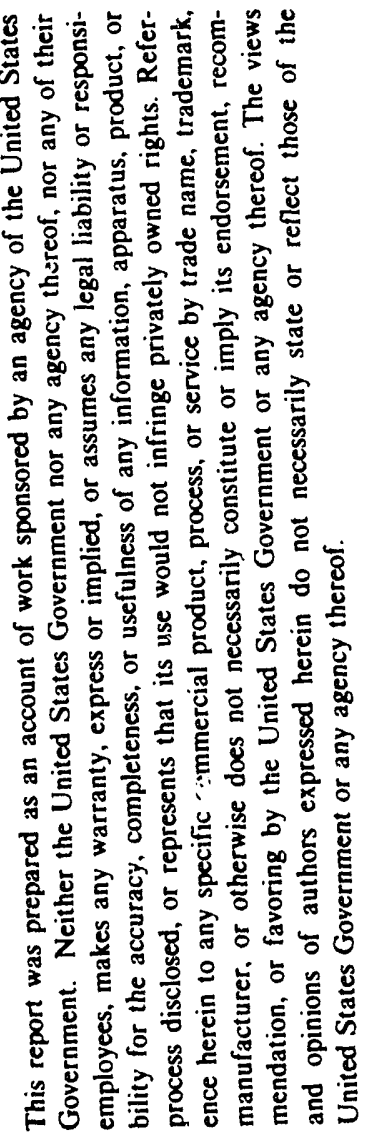

The large dynamic shear strength of certain ceramic compounds is central to the superior impact and penetration resistance of these materials. Further improvements in strength properties continue to be achieved through improved manufacturing methods and the enhancement of chemical and microstructural features. The dynamic shear behavior is commonly determined through controlled impact methods in which the transient yield strength under loading conditions of uniaxial strain (the Hugoniot elastic limit) is measured. The indentation hardness test is an alternative method for examining strength properties of ceramics which is attractive because of the relatively expedient and cost-effective nature of the experiment.

The strength properties of selected ceramics measured by the two test methods are examined in the present work. A degree of correlation between strength data obtained from the two methods is observed and some of the deformation mechanisms which may lead to discrepancies in correlation are discussed. In certain cases the indentation hardness test may provide a useful alternative or comple-

Sponsored by the U.S. Department of Energy and conducted under the auspices of the U. S. Department of Energy under Contract DE-AC04-76DP00789. 
ment to the dynamic impact test although there is a need to better understand the deformation processes leading to the strength measurements obtained from the two experimental methods.

\section{BACKGROUND}

There are at least three critical parameters to which the shear strength of a brittle material can be expected to show sensitivity. These are, respectively, the confining pressure, strain rate and size scale. Consideration of these parameters as they relate to the dynamic strength measured in an impact experiment (the Hugoniot elastic limit) and the static strength determined in an indentation hardness test suggests the potential value in the comparison of strength data from the two experimental methods.

The Hugoniot elastic limit in an impact experiment is established by the amplitude of the dwell or plateau in a large-amplitude wave structure which has been established over a reasonable propagation distance, and which separates the first elastic wave from the following deformation wave. The Hugoniot elastic limit is usually (although not always) reached through an elastic wave whose risetime is vanishingly small with respect to current wave measurement resolution ( 1 to $10 \mathrm{~ns}$ ). The thickness of this first wave, however, does not determine the spacial scale of the material tested for strength in an impact-induced shock-wave experiment. It is the second deformation wave within which the shear strength limit is established, which determines the amplitude of the Hugoniot elastic limit. The deformation wave is usually observed to have a measurable thickness providing that its amplitude is less than a few times that of the elastic wave. The thickness of the deformation wave is strongly dependent on the amplitude of the stress jump through the deformation wave $[1,2]$ and dimensions of about 10 
to $100 \mu \mathrm{m}$ have been established for the present ceramics when shock loaded to stresses less than 50 $\mathrm{GPa}$. The deformation wave thickness provides the specimen size scale in a shock-wave experiment. This scale compares well with the 10 to $50 \mu \mathrm{m}$ scale of the region under a hardness indentor.

The state of deformation in a planar-impact shockwave experiment is one of uniaxial strain. Consequently, when yield is achieved the material is in a high state of confinement. When the axial stress $\sigma_{x}$ achieves the Hugoniot elastic limit, $\sigma_{x}=\sigma_{\text {hel }}$, the lateral stresses are,

$$
\sigma_{y}=\sigma_{z}=f(v) \sigma_{h e l},
$$

and the mean stress is,

$$
p=\left(\sigma_{x}+\sigma_{y}+\sigma_{z}\right) / 3=g(v) \sigma_{h e l},
$$

where $f(v)$ and $g(v)$ are common functions of the Poisson's ratio $v$.

The degree of confinement differs starkly from the case of yield under uniaxial stress loading where $\sigma_{y}=\sigma_{z}=0$ and $p=Y / 3 \quad(Y=$ compressive yield strength). The state of confinement of the material at yield in a static hardness test is complicated but more closely related to the high value achieved under planar impact conditions.

Although scale and state of confinement are comparable in the dynamic impact and indentation hardness experiments, the rates of deformation in the two test methods differ by orders of magnitude. Strain rates in a hardness test will be less than about $10^{-2} / \mathrm{s}$, whereas strain rates in the impact tests, determined from risetimes of the deformation wave, are on the order of $10^{5} / \mathrm{s}$ to $10^{6} / \mathrm{s}$.

Thus, it is argued that strength differences between the shock-wave and indentation hardness measure- 
ments is primarily a consequence of strain-rate sensitivities rather than size scale or confiningpressure effects.

\section{TEST METHOD AND MATERIALS}

In the present study, a dynamic or shock wave measurement of strength is achieved through the use of a propellant gas gun which accelerates a projectile carrying a disc-shaped sample of the ceramic of interest to velocities as high as several kilometers per second [3]. The ceramic sample undergoes planar impact with a similarly-shaped stationary ceramic sample. A thick disc of lithium fluoride is bonded to the back of the stationary ceramic disc and performs as a transparent laser window [4] for the velocity interferometry (VISAR) system [5]. The VISAR monitors the time-resolved velocity at the ceramic-lithium fluoride interface, providing a measure of the shock wave profile caused by the high-velocity impact. The amplitude of separation of the two-wave structure in this shock wave measurement determines the dynamic strength or the Hugoniot elastic limit for the material under test.

Indentation hardness measurements were obtained through the Knoop indentation hardness method and were performed at the Army Research Laboratory [6].

High strength ceramics tested in the present program were acquired from a number of sources. In several cases the same ceramic obtained from several different suppliers was tested, allowing some comparisons of material property variations due to differences in impurity content, microstructure and ceramic preparation. At present, six different monolithic ceramic materials have been investigated. These are aluminum nitride, aluminum oxide, boron carbide, silicon carbide, titanium diboride and zirconium dioxide. Longitudinal and shear 
sound velocities, and densit:es were determined for all ceramics tested. Appropriate data for each ceramic are provided in Table 1. Optical and SEM microstructural examinations have been performed on some of the samples.

The aluminum nitride (AN) under investigation in the present study was acquired from the Dow Chemical Company and is the same ceramic tested in recent shock-compression studies [7]. According to the supplier the hot-pressed aluminum nitride tiles have a nominal porosity of $1 \%$ and grain size of $2 \mu \mathrm{m}$. Ultrasonic and density measurements made in this laboratory indicated a sample-to-sample variation of about $2 \%$ in these properties, with the average value reported in Table 1.

The first aluminum oxide (A1), supplied by the Italian manufacturer Industrie Bitassi, contained a significant fraction of glassy phase. The second material (A2) is the relatively high-purity Coors $\mathrm{AD}-995$ alumina.

Boron carbide from two different suppliers was also tested. The first boron carbide material (B1), supplied by Eagle Picher Industries, has a nominal grain size of $10 \mu \mathrm{m}$. The principal contaminant in this ceramic, revealed by electron probe microanalysis, is iron which occurrs within voids and other sites distributed quite heterogeneously (relative to the grain size) throughout the material. The second boron carbide (B2), supplied by Dow Chemical Company, has a nominal grain size of about $3 \mu \mathrm{m}$.

The silicon carbide (S1) examined in the study was supplied by Eagle Picher Industries. This ceramic has a nominal grain size of $7 \mu \mathrm{m}$ and about $1 \%$ porosity in the form of spherical cavities on grain boundaries. 
Titanium diboride from two different suppliers was also tested. The titanium diboride (T1), supplied by Eagle Picher Industries, has a nominal grain size of $12 \mu \mathrm{m}$. Both SEM and density measurements indicates several percent porosity in this ceramic. The second titanium diboride (T2) was provided by Cercom Incorporated. This ceramic is higher density, and optical microscopy indicate a nominal grain size of about $30 \mu \mathrm{m}$.

Several types of zirconium dioxide were tested in this study. The first zirconium dioxide material (Z3), is a $12.5 \mathrm{~mol} \%$ yttria-stabilized cubic zirconia supplied by McDonald Refractory. A nominal grain size of $15 \mu \mathrm{m}$ was determined, and porosity in this material is approximately $4 \%$. The second zirconium dioxide ( $\mathrm{Z} 1$ and $\mathrm{Z} 2$ ) is a high quality $3 \mathrm{~mol} \%$ yttria-stabilized zirconia of nearly $100 \%$ tetragonal phase. This material was supplied by Sumimoto Electric Industry in two batches which differed by about $1 / 2 \%$ in initial density. Shock wave properties for these zirconia materials have been reported previously [8]. Shock wave properties of the other ceramics are discussed elsewhere $[3,9]$. 
Table 1: Indentation Hardness and Dynamic Strength Data

\begin{tabular}{|l|c|c|c|c|c|}
\hline \multirow{2}{*}{ Material $^{(a)}$} & Density & $C_{l}$ & $C_{s}$ & $\begin{array}{c}\text { Dynamic } \\
\text { Yield }^{(\mathrm{b})}\end{array}$ & Hardness \\
\cline { 2 - 6 } & $\left(\mathrm{kg} / \mathrm{m}^{3}\right)$ & $(\mathrm{km} / \mathrm{s})$ & $(\mathrm{km} / \mathrm{s})$ & $(\mathrm{GPa})$ & $(\mathrm{GPa})$ \\
\hline $\mathrm{AlN}(\mathrm{AN})$ & 3254 & 10.73 & 6.32 & 5.5 & 10.6 \\
\hline $\mathrm{Al}_{2} \mathrm{O}_{3}(\mathrm{~A} 1)$ & 3555 & 9.28 & 5.47 & 3.6 & 10.6 \\
\hline $\mathrm{Al}_{2} \mathrm{O}_{3}(\mathrm{~A} 2)$ & 3890 & 10.56 & 6.24 & 4.3 & 14.5 \\
\hline $\mathrm{B}_{4} \mathrm{C}(\mathrm{B} 1)$ & 2517 & 14.04 & 8.90 & 13.7 & 26.2 \\
\hline $\mathrm{B}_{4} \mathrm{C}(\mathrm{B} 2)$ & 2506 & 14.07 & 8.87 & 15.1 & 25.6 \\
\hline $\mathrm{SiC}(\mathrm{S} 1)$ & 3177 & 12.06 & 7.67 & 12.5 & 22.3 \\
\hline $\mathrm{TiB}_{2}(\mathrm{~T} 1)$ & 4452 & 10.93 & 7.30 & 11.6 & 19.0 \\
& & & & $(5.4)$ & \\
\hline $\mathrm{TiB}_{2}(\mathrm{~T} 2)$ & 4509 & 10.79 & 7.43 & 15.2 & 19.6 \\
\hline $\mathrm{ZrO}_{2}(\mathrm{Z1})$ & 5602 & 6.61 & 3.54 & 3.2 & 8.5 \\
\hline $\mathrm{ZrO}_{2}(\mathrm{Z2})$ & 6028 & 7.11 & 3.72 & 8.9 & 11.4 \\
\hline $\mathrm{ZrO}_{2}(\mathrm{Z3})$ & 5954 & 6.87 & 3.63 & 7.4 & 10.7 \\
\hline
\end{tabular}

(a) Code is identified in the text.

(b) Numbers in parentheses are lower yield for $\mathrm{TiB}_{2}$ (see text). 


\section{RESULTS AND DISCUSSION}

Results of the static indentation measurements and the impact Hugoniot elastic limit measurements for the ceramics tested are provided in Table 1. An equivalent dynamic yield strength is determined through the relation

$$
Y_{d}=2 \frac{C_{s}^{2}}{C_{l}^{2}} \sigma_{h e l},
$$

where $C_{s}$ and $C_{l}$ are the shear and longitudinal sound velocities, and where constant elastic properties are assumed for the materials within the yield surface.

The dynamic yield and hardness measurements are correlated in Figure 1. It is instructive to compare the data to earlier results $[10,11]$ in which some of the same ceramics were investigated. A noticeable difference is the somewhat weaker correlation of static and dynamic strength observed in the more recent data. The general trend, however, is similar with a slope of unity and the magnitude of dynamic yield of order one-half of the static hardness.

The spread in dynamic strength values of some of the materials is due to the sensitivity of the VISAR diagnostic to initial yield in the porous samples (about $1 \%$ to $2 \%$ in most of the ceramics). The first break in the elastic wave profile associated with the Hugoniot elastic limit will differ markedly for the same ceramic for variations only in initial porosity. It is expected, however, that subsequent or postyield strength hardening occurs as inelastic pore collapse proceeds during the shock-compression process. It is suspected that the indentation hardness test is less sensitive to yield onset and provides a strength measurement which averages over a larger deformation strain. Consequently, the indentation hardness measurement would be less sensi- 


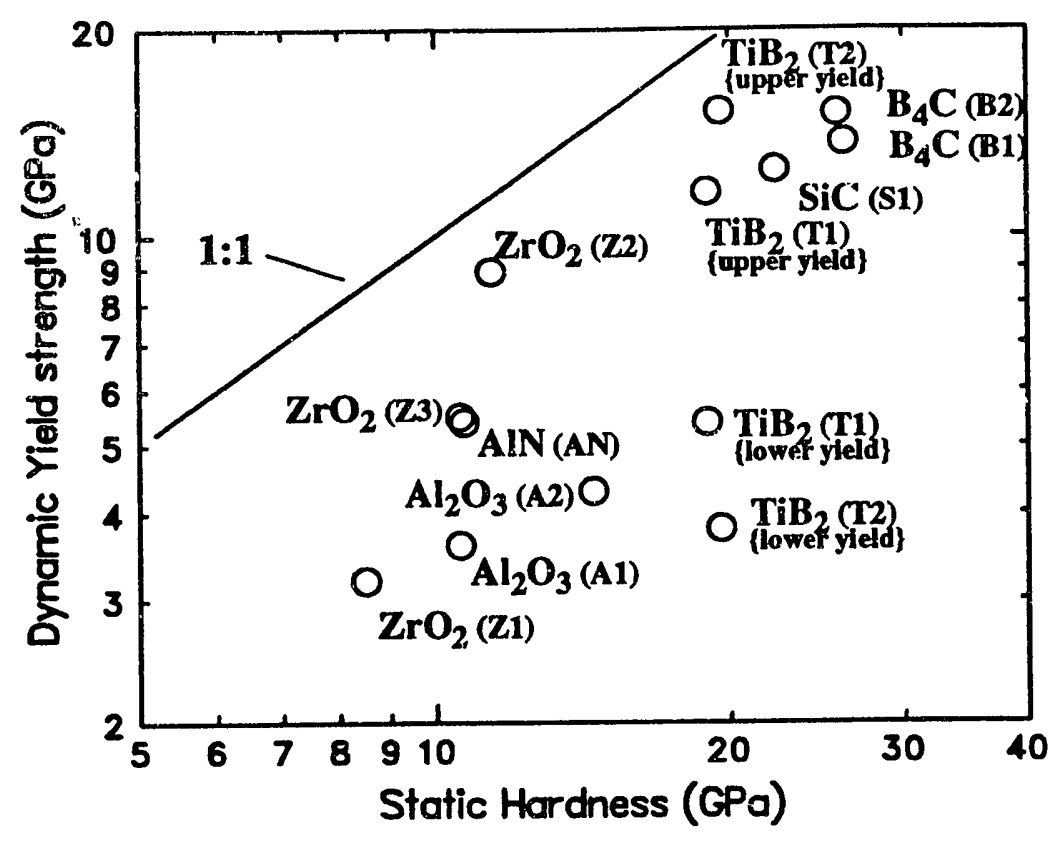

Figure 1. Dynamic strength and indentation hardness of selected ceramics.

tive to moderate variations in porosity in a specitic ceramic.

This difference in sensitivities of the two test methods appears to explain the strength measurements for the two tetragonal zirconia samples which differed only in initial porosity, and probably explains the two titanium diboride points (upper yield) whose density difference is most likely also related to a small porosity difference. As seen in Figure 1, the dynamic strength for these two materials is observed to depend sensitively on the variations in porosity whereas indentation hardness measurements are relatively insensitive to these same variations. The dynamic yield for the two aluminum oxides and the cubic zirconium dioxide, which seem to be below the general trend of the data may also be related to the excessive porosity in these materials. The larger glassy component in the $\mathrm{Bi}$ - 
tassi alumina probably accounts for the significant reduction in indentation hardness compared to that of Coors AD-995 alumina.

Titanium diboride is unusual in that time-resolved controlled impact experiments indicate a complex two-step yield process for this material [9]. The shock data suggests a secondary nonpervasive yield at about 4 to $5 \mathrm{GPa}$ shear stress which quickly saturates and is followed by onset of pervasive shear yield at about 12 to $15 \mathrm{GPa}$. It is interesting to note in Figure 1 that indentation hardness and dynamic yield for this material correlates with the general trend of the data if the upper yield is considered.

Impact experiments on boron carbide identify a high initial dynamic shear strength as is shown in Figure 1, but dramatic shear strength softening occurs with subsequent deformation. This behavior has not been observed in the other ceramics tested. The comparatively high indentation hardness measurements for boron carbide do not reflect this softening, suggesting that it is strictly a dynamic effect - possibly local thermal softening or a lattice instability in the boron carbide structure.

\section{SUMMARY}

It can be argued that shock compression and indentation hardness methods test the strength characteristics of material under similar states of confining pressure and of similar size scale, differing principally in the rate of loading. Comparisons of shock wave and indentation hardness measurements show a reasonable correlation in strength values between the two test methods. Nominal agreement in magnitude suggests that strain rate effects in these ceramic may be weak. It is also suggested that differing sensitivities of the two test methods to modest variations in initial porosity may account for much of the correlation scatter. It is suggested 
that indentation hardness tests average over larger strains, providing a strength measure closer to that of the fully dense material. In contrast, the high resolution of the shock-wave VISAR diagnostic leads to more detailed information on porosity sensitivity and deformation hardening. Improved understanding of deformation details in the two test methods should lead to enhanced material strength data for computational model development and application.

\section{ACKNOWLEDGEMENTS}

The author gratefully acknowledges the support of Michael Slavin and coworkers at the Army Research Laboratory, Watertown, MA, for providing the static indentation hardness measurements on the present suite of ceramics 


\section{REFERENCES}

[1] D. E. Grady, Appl. Phys. Let. 38, pp. 825-826 (1981).

[2] J. W. Swegle and D. E. Grady, J. Appl. Phys. 58, pp. 692-710 (1985).

[3]D. E. Grady, in: Shock Compression of Condensed Matter-1991, edited by S. C. Schmidt, R. D. Dick, J. C. Forbes, and D. G. Tasker (Elsevier Science Publishers B. V. New York), 1992, pp. 455458.

[4] J. L. Wise and L. C. Chhabildas, in: Shock Waves in Condensed Matter, edited by Y. M. Gupta, (Plenum, New York), 1986, pp. 441-444. [5] L. M. Barker and R. E. Hollenbach, J. Appl. Phys. 43, pp. $4669-4679$ (972).

[6]M. J. Slavin, (private communication) August, 1991.

[7] Z. Kosenberg, N. S. Brar, and S. J. Bless, J. Appl. Phys., 70 pp. 167-177 (1991).

[8]D. E. Grady and T. Mashimo, J. Appl. Phys., 71, pp. 4868-4878 (1992).

[9]D. E. Grady, in Proceedings of the XIII International AIRAPT Conference, Bangalore, India, 1991, pp. 641-650.

[10]C. F. Cline, (private communication) March, 1989.

[11]J. J. Gilman, J. Appl. Phys. 41, pp. 1664-1674 (1970). 

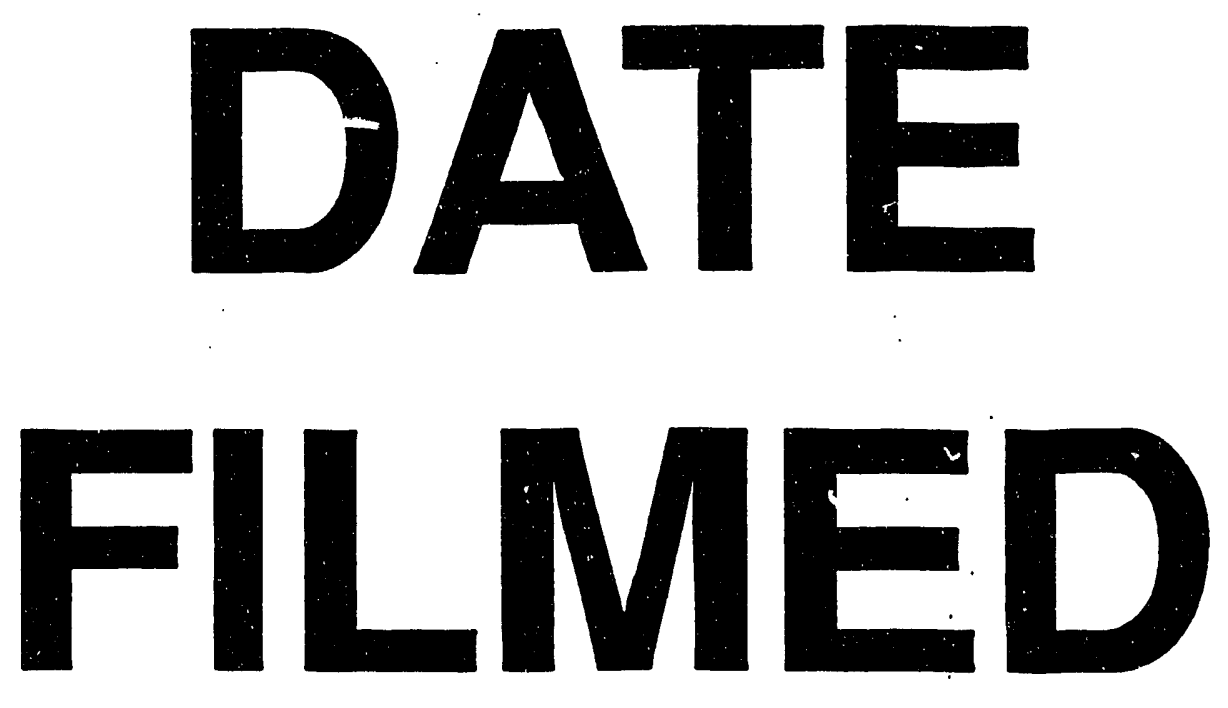

$10 / 13 / 93$
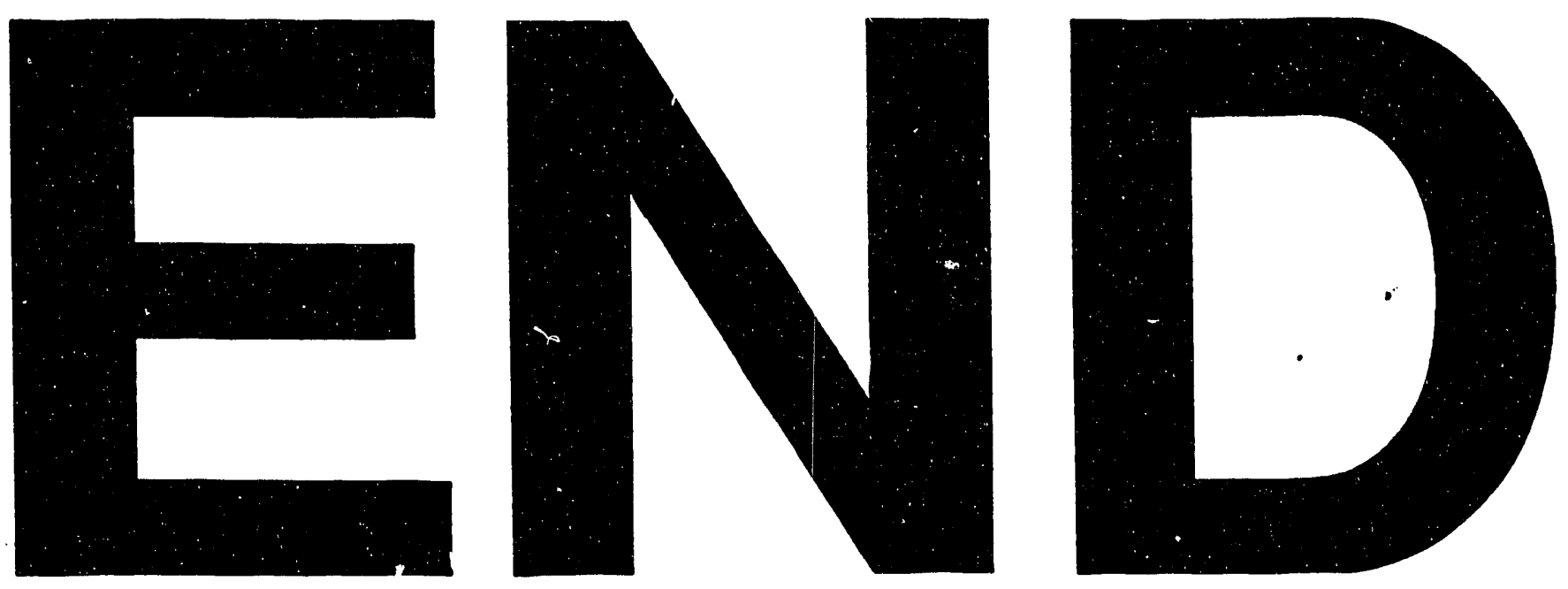
